\title{
Exaggeration in Congratulatory Expressions in Jordanian Arabic: A socio Pragmatic Study
}

\author{
Abeer Ahmad Moh`d Khatatbeh ${ }^{1 *}$, Fawwaz Al-abed Al-Haq ${ }^{1}$, Mahmoud Al Sobh² \\ ${ }^{1}$ Yarmouk University, Irbid, Jordan \\ ${ }^{2}$ Ajloun National University, Ajloun, Jordan
}

Corresponding Author: Abeer Ahmad Moh`d Khatatbeh, E-mail: abeerahmad261@yahoo.com

\section{ARTICLE INFO \\ Article history \\ Received: February 11, 2018 \\ Accepted: April 29, 2018 \\ Published: September 01, 2018 \\ Volume: 7 Issue: 5 \\ Advance access: July 2018}

Conflicts of interest: None

Funding: None

\begin{abstract}
This study is an attempt to investigate exaggeration in congratulatory expressions that are used by Jordanian Arabic speakers. From a socio pragmatic view exaggeration in congratulatory expressions has not been thoroughly studied in Jordan. Therefore, this study sheds light on expressions used by Jordanian Arabic speakers and the effect of sociological factors, such as: age, gender and level of education on using these expressions in the Jordanian society. In order to achieve the objectives of the study, a questionnaire was developed and distributed to 88 male and female participants randomly selected from Irbid. The findings of the study reveal the most prominent exaggerated expressions that express congratulation in Jordanian Arabic. The findings also reveal that the social variables: age, gender and level of education affect the use of these expressions in certain situations. They also reveal the importance of studying the language in relation to social variables.
\end{abstract}

Key words: Exaggeration, Congratulation, Politeness Theory, Discourse, Pragmatics, Semantics

\section{INTRODUCTION}

Jordanian Arabic is rich with expressions that express exaggeration when people congratulate each other in happy occasions and success. Therefore, Jordanian Arabic has unlimited set of social and linguistic terms that have a power in conveying the intended meaning. The role of discourse appears to preface sayings, reactions, actions including the expressions of exaggeration. People in a certain society use language as a tool of social interaction in a way that is suitable to the cultural values and norms of that society. Arabic is a language that is known with opulent words and vocabulary. Diction is chosen carefully in which it suits a situation. In the sense of congratulation, people use good diction that arouses the feeling of pretty speech and conveying meaning. congratulation is considered one of social situations in which people communicate to express certain feelings and attitudes. Al-Khatib (1997:167) states, "congratulation and thanking, like apologizing, are social acts aimed at maintaining good relations between individuals". Congratulation is one of the wellknown social customs in any society, speakers of Jordanian Arabic use different expressions and terms and follow certain strategies in order to express this social custom. One of these strategies is exaggeration. people tend to exaggerate each other to make things seem better than it really is. They use expressions like (ألف ألف مليون مبروووووك) (alf alf million mabru: k) (A thousand thousand million congratulations) to express exaggeration in showing happiness for a certain occasion. One may say: (واله طرت من الفرحة) (Wallah Tert min al- farhah), this kind of exaggeration is used to emphasize strong emotion and honesty. The literal meaning of the utterance is not the intended meaning.

\section{Discourse}

Hall (1996: 201) defines discourse as "a group of statements which provide a language for talking about - i.e. a way of representing- a particular kind of knowledge about a topic".

Hall (1996: 205) says "Discourses are ways of talking, thinking or representing a particular subject or topic. They produce meaningful knowledge about that subject. This knowledge influences social practices, and so has real consequences and effects.

Not only discourse plays a fundamental role in communication, but also context is very important to understand others. Context plays the main role in determining the intended meaning. Kaburise (2005:8) defines context as "the "binding agent' or the channel through which the language of an utterance creates the intention (function) of the utterance".

\section{Semantics and Pragmatics}

Filip (2008:8) defines semantics as: " the study of meaning expressed by elements of any language, characterizable as a symbolic system. Yule (1996:3) defines pragmatics as the study of speaker's meaning. It studies the meaning as communicated by a speaker and interpreted by a hearer. More- 
over, Pragmatics is the study of contextual meaning. It studies the interpretation of what people mean in a certain context and the role of context upon what is said. Cruse (2006:136) says that Semantics draw a description for the meaning of words, while pragmatics draw a description for the use of words in context to conclude the intended meaning. there is a relationship between connotative meaning and exaggeration. That is because exaggeration is an overstatement with words that the meaning cannot be taken literally. There is a message behind the utterance in certain occasion.

Jakobson (1960:353) states six factors that any effective verbal communication contains; the addresser, addressee, context, message, contact, and code. These factors can 't be isolated from each other.

\section{Meaning}

There are two kinds of meaning, in the field of semantics, denotative meaning and connotative meaning. Yule (2006:113) called the two types of meaning as, conceptual meaning and associative meaning. Dickens (2014:2) defines denotative meaning as " involving the overall range of a word or multi- word unit or, by extension syntactic structure". Dickens (2014:2-3) defines connotative meaning as "those kinds of meanings which do not involve the extensional range of a word/multi- word unit/syntactic structure".

\section{Politeness Theory}

Holmes (2001:275) argues that, in order to be polite in a certain context one needs knowing how to express a range of speech function in a certain culture in an appropriate way. So, what is polite in a certain culture and society might be impolite in another culture.

Yule (1996:60) defines Politeness as "the means employed to show awareness of another person's face".

Tannen $(2007: 3)$ states that the difference in gender is existence and it is obvious in the ways of speaking.

Song (2010:877) says that language reflects the value system for certain society because language is a social phenomenon as it is known. Thus, social role, status, sex and age affect the language.

Gharaybeh (2014:4) states that, the Jordanian society is known for solidity, and is highly correlated with reference to the religious traditions and culture.

McCarthy and Carter (2004:152) point that most scholars agree that exaggeration is not a lie. Exaggeration is socially acceptable while lying is socially unacceptable. Lying is used to hide reality, but exaggeration is used to express and state hide emotions. The speaker tries to reveal the evaluative context of exaggeration to express effective meaning. The speaker does not use exaggeration to avoid inappropriate conditions as in the case of lying.

\section{STATEMENT OF THE PROBLEM}

Exaggeration is a sociolinguistic phenomenon in the Jordanian community, people use different expressions that express exaggeration in showing happiness for somebody`s success or good luck. People make things seem larger and better than it is in real.

It is noticeable that there is no serious attention paid to exaggeration. In other words, exaggeration and congratulation are studied separately, but the current study is an attempt to examine them together. This study takes a first step toward a comprehensive explanation of exaggeration and congratulation at the same time "exaggeration in congratulatory expressions". Moreover, this study provides a broad discussion of these expressions that are used in Jordanian Arabic. Such study would be an academic references for scholars, and fill a gap in related literature. It also investigates the effect of social factors, such as: age, gender and level of education on using these expressions in the Jordanian society.

\section{PURPOSE AND QUESTIONS OF THE STUDY}

The main aim of this study is to analyze the exaggeration in congratulatory expressions used by Jordanians. In particular, this study attempts to answer the following questions:

1- What are the most prominent exaggerated expressions that express congratulation in Jordanian Arabic?

2- To what extent do gender, age, and level of education affect the use of these expressions?

\section{SIGNIFICANCE OF THE STUDY}

This research is an attempt to familiarize people with exaggerated congratulation expressions used in everyday life in different social situations in which each expression is used in Jordanian society. This study is an attempt to familiarize curriculum designers of the importance of including such expressions in Jordanian textbooks to achieve the linguistic socialization in fulfilling the functions of language.

\section{LIMITATION OF THE STUDY}

The current study is limited to exaggeration in light of politeness theory and positive meaning. Moreover, the data of the study are collected from the northern part of Jordan, namely, Irbid, from different ages, gender and level of education. Furthermore, the study is limited to spoken exaggeration expressions in the topic of exaggeration.

\section{DEFINITION OF TERMS}

Congratulation can be considered an acknowledgement of the achievement or good fortune of others. It is the act of expressing pleasure for somebody`s success or happy occasion. The Longman Dictionary of Contemporary English defines congratulation as "when you tell some people that they are happy because they have achieved something or because something nice has happened to them".

The term "exaggeration" is derived from "Latin exaggerātiōn-(stem of exaggerātiō, equivalent to exaggerōt(us) which is defined in "Dictionary. com" as follows: to magnify beyond the limits of truth; overstate; represent disproportionately and increase or enlarge abnormally. Exaggeration is a rhetorical device or figure of speech. The speaker emphasizes 
strong feelings toward the hearer and make strong impressions. It is not meant to be taken literally because it is considered a figure of speech. This means that exaggeration is an expression that exceeds the literal meaning and includes more semantic attributes of expressing something.

\section{LITERATURE REVIEW}

Christodoulidou (2011:143) describes two types of hyperbole: Overstatement of Numbers and Quantity in which The speaker uses a large number of times, years, etc to show exaggeration in congratulatory expressions, such as: "Alf alf mabrwk". (a thousand thousand congratulations) and Impossible Description in which the speaker tries to show something that cannot be expected to happen or exist e.g. the expression "Tert men alfarhah". (I flew due to happiness) Actually, nobody can fly because of happiness or pleasure. This is an impossible description. This example cannot be taken literally, but figuratively. Searl (1976: 12) classifies the verb congratulate, in the classification of illocutionary acts, under the class of expressive. Can (2011:23) states that in congratulation, the speaker acknowledges and expresses the feeling for the purpose of satisfying the social expectation, even if the speaker does not have genuine feelings about the occasion. Smith (1969:54) classifies exaggeration into two types: auxesis and meiosis.

People often use statements that are not true to emphasize the real situation. Moreover, some people express their strong feeling in a happy occasion in a way that makes their feeling more noticeable to others; they make things look larger. In other words, people use exaggeration in their communication. Al-Khatib (1997:162) introduces an example "by saying '....alf mabruuk', 'a thousand of congratulations to you". Holmes $(2001: 268)$ states that to be polite involves the speaker to speak appropriately with reference to relationship. Christodoulidou (2011:145) states that exaggeration can be identified by numerical expressions of year and times. Claridge (2011:1) says that the use of exaggeration attracts the listeners in a powerful way. Henkemans (2013:1-2) says that hyperbole is a stylistic rhetorical device in which the speaker makes statements obviously exaggerated.

There are five Arabic studies about exaggeration on one hand, and congratulation on the other. Emery (2000) examines politeness formulas of greeting, congratulation, and commiserating in Omani Arabic that are made by old and young people. Hafez (2004) in (Bani Melhem, 2017)) examined the hyperbolic expressions in Egyptian Arabic and British English with regard to semantic theory and pragmatic functions.etc. Omar, et. al. (2009) have a sociolinguistic study of hyperbole in Iraqi Arabic translations of the Qur'an, Saheeh International Translation (1997). Al-Shboul and Huwari (2016) examines congratulation strategies that used by Jordanian EFL post graduate students and the strategies of positive politeness in congratulation speech acts.

\section{METHODOLOGY}

This section includes a description of the population and the sample of the study, instruments of the study and data analysis procedures. Moreover, it clarifies the validity and reliability of the research instrument.

\section{Population and Sample of the Study}

The population of the current study consists of 88 Jordanian male and female participants, who are native speakers of Jordanian Arabic, from Yarmouk University in Irbid, North Jordan. The participants are familiar with the culture and traditions of Jordan. For the gender variable, participants were divided into 37 (42\%) males and 51 (58\%) females. Participants whose ages range between 18-49 are included from different levels of education (BA, MA and Ph.D).

\section{Instruments of the Study}

In order to collect the required data for the study, the researcher adopts a personal observation method, an interviewing method and a questionnaire written in Arabic to facilitate the task.

\section{Observation}

In order to harvest the required objectives of this study, exaggeration in congratulatory expressions in Jordanian Arabic, the researcher uses the direct observation method from every day conversations in most congratulatory occasions.

\section{Interview (in Arabic)}

The researcher interviews some native speakers of Arabic in Irbid of different genders, ages, and levels of education to discuss the exaggerated expressions they usually and frequently use in congratulation, then their responses are recorded.

\section{Questionnaire}

The questionnaire of this study is divided into two sections: the first is designed for personal information and the second is designed to find out the exaggerated congratulatory expressions that Jordanians usually and frequently use in their interactions during happy occasions.

\section{Validity of the Instrument}

In order to achieve the validity of the instrument, Professors who are linguists and sociolinguists, at the Department of English Language and Literature at Yarmouk University were asked to provide their comments and suggestions, which were taken into consideration in the final version of the questionnaire.

\section{Data Analysis}

The researcher used simple statistics of frequency, percentages means and the three way ANOVA. The questionnaires were collected and the data were checked. After that, the data were processed and statistically computed and ana- 
lyzed. Information was interpreted and descriptive analysis was used.

\section{FINDINGS AND DISCUSSION OF THE STUDY}

\section{Findings Related to the First Question}

'What are the most prominent exaggerated expressions that express congratulation in Jordanian Arabic?'

An analysis of the data collected of exaggeration in congratulatory expressions is carried out, besides an analysis of questionnaire. The first question was raised to investigate the most prominent exaggerated expressions that express congratulation in Jordanian Arabic. The current study reveals the most prominent expressions that express exaggeration in congratulation and the percentages of their occurrence. Some expressions show the identification of exaggeration that includes "overstatement of "numbers and quantity" and " impossible description". Moreover, some expressions express praying to Allah to give the hearer more success and health through the life. Furthermore, some expressions are controlled with religious marks. The current study reveals that the expression "mafa? allah" ما شاء اله has the highest percentage $92.4 \%$ with the mean of 4.62 , the expression " alf mabruuk" الف مبروك has the percentage 91.8 with the mean of 4.59 , the expression " btestahal kull xayr" has the percentage $86.2 \%$ with the mean of 4.31 , the expression "frehtellak men kull galby" has the percentage $84.4 \%$ with the mean of الف الف الف مبروك "alf alf alf mabruuk" has the percentage $75.4 \%$ with the mean 3.77 . This shows the identification of exaggeration which includes " Over-

Table 1. Mean and standard deviation for the social variables

\begin{tabular}{lccc}
\hline & Mean & Standard deviation & $\mathbf{N}$ \\
\hline Gender & & & \\
Male & 3.38 & 0.857 & 37 \\
Female & 3.07 & 0934 & 51 \\
Age & & & \\
$18-30$ & 3.30 & 0929 & 63 \\
$31-49$ & 2.96 & 0830 & 25 \\
Education & & & \\
BA & 3.33 & 1.016 & 34 \\
MA & 2.97 & 0.716 & 27 \\
PhD & 3.26 & 0.932 & 27 \\
Total & 3.20 & 0.911 & 88 \\
\hline
\end{tabular}

statement of numbers and quantities". Numerical exaggeration is the most common exaggerated sign in congratulation and they occur frequently. Furthermore, Other comprehensive extreme quantifiers, such as: (all, every) "kull" are also exaggerated signs in congratulatory expressions and they also occur frequently.

Impossible description is the second method of identifying exaggeration beside Overstatement of numbers and quantities. This method shows descriptions that are not possible to occur. They exceed manner, reality, condition and feeling. In the expression "rafa3et rasna" (you lift our head), the literal meaning cannot be taken in consideration. A success does not have hands and lift the head, the speaker shows that he is happy and this success makes high status for him among people.

\section{Findings Related to the Second Question}

'To what extent do gender, age, and level of education affect the use of these expressions?'

In order to examine the affect for the social variables: age, gender and level of education in the use of exaggeration in congratulatory expressions, the researcher used means, standard deviation and three way ANOVA to determine if there was a statistically significant difference due to these variables. This is shown in Table (1).

Table 1 shows the means and standard deviation for the social variables: age, gender and level of education.

Table (2) shows that there are no statistically significant differences in using exaggeration expressions due to gender $\mathrm{f}=2.197 \mathrm{p}=0.142$, age $\mathrm{f}=2.498 \mathrm{p}=0.118$ and level of education $\mathrm{f}=0.540 \mathrm{p}=0.585$.

The researcher thinks that the sample is homogeneous, it is taken from one city that has the same environment, culture and it has the same way on communication. Furthermore, the use of extra exaggerated congratulation is cultural specific. Jordanians in particular and Arabs in general tend to exaggerate not only in congratulation but in other sociolinguistic functions, such as greeting, condolences and intimacy among many other expressions. The study investigation shows that Jordanians prefer to use exaggeration as it has a positive effect towards the hearer, over love for the person and a kind of imitation.

\section{CONCLUSIONS}

The aim of the current study is to investigate and analyze exaggeration in congratulatory expressions that are more frequently used by the speakers of Jordanian Arabic. Moreover,

Table 2. Three way ANOVA for the social variables: Age, gender and level of education

\begin{tabular}{lccccc}
\hline Source & Type III sum of squares & df & Mean square & F & Sig. (p) \\
\hline Gender & 1.768 & 1 & 1.768 & 2.197 & 0.142 \\
Age & 2.010 & 1 & 2.010 & 2.498 & 0.118 \\
Level of education & 0.868 & 2 & 0.434 & 0.540 & 0.585 \\
Error & 66.774 & 83 & 0.805 & & \\
Corrected total & 72.150 & 87 & & & \\
\hline
\end{tabular}


it aims to show the the affect of gender, age and level of education on the use of these expressions.

Based on the research findings, exaggerated expressions can be identified by the use overstatement of numbers and quantities. Numerical exaggeration is the most common exaggerated signs in congratulation and they occur frequently, such as the expression "alf mabrwk" (a thousand congratulation) has the percentage $91.8 \%$ and the expression " alf alf alf mabrwk" (a thousand, thousand, thousand congratulations) has the percentage $75.4 \%$. Other comprehensive extreme quantifiers, such as: (all, every) “ kull” are exaggerated signs such as the expression " btestahal kul xayr" (you deserve all benevolent) has the percentage $86.2 \%$. Moreover, impossible description shows descriptions that are not possible to occur. In this respect, the meaning must be taken figuratively not literally such as the expression "Tert men alfarhah".

Males use exaggeration in congratulatory expressions more than females. For the effect of age, the results show that people who are less than 30 years old use exaggeration in congratulatory expressions more than people who are above 30. The effect of level of education shows that BA participants use 33 exaggerated expressions with higher percentages than MA and ph.D.

\section{RECOMMENDATIONS}

The present study suggests the following recommendation:

1- A contrastive study of exaggerated congratulatory expressions in Jordanian Arabic and any other language may be a topic to investigate.2- Further research may examine the use of exaggeration in congratulation in written forms in newspapers, media or other social media, such as: Face book, Wattsapp ....etc.3-The researcher recommends a study on exaggerated congratulatory expressions in other societies in Jordan as in the Urban and Bedouin societies.4-It is recommended to familiarize curriculum designers of the importance of including such expressions in Jordanian textbooks.

\section{REFERENCES}

Al-Khatib. M. A. (1997). Congratulation and Thank you Announcements in Jordanian Newspapers: Cultural and communicative Functions. Language, Culture and Curriculum, 10(2), Pp.158-169.

Al-Shboul, Y., and Fathi Huwari, I. (2016). Congratulation Strategies of Jordanian EFL Postgraduate Students. Zarqa University: Jordan, 6(1).

Bani, M., Rana Faleh, A. (2017). A Socio-Pragmatic Study of Hyperbolic Expressions in Colloquial Jordanian Arabic. Master of Arts. Department of English Language and Literature, Yarmouk University.
Can, H. (2011). Across-Cultural study of Speech Act of Congratulation in British English and Turkish using a Corpus Approach. (p.2).

Christodoulidou, M. (2011). "Hyperbole in everyday conversations". Proceedings of the $19^{\text {th }}$ International Symposium on Theoretical and Applied Linguistics. 19: 143-152.

Claridge, C. (2011). Hyperbole in English. A Corpus-Based Study of Exaggeration. Cambridge University Press. 2011. xiii-301.

Cruse, A. (2006). A Glossary of Semantics and Pragmatics. Edinburgh: Edinburgh University Press.

Emery, P. G. (2000). Greeting, congratulating and commiserating in Omani Arabic. Language, Culture and Curriculum, 13(2), 196-217.

Filip, H. (2008). What is Semantics, What is Meaning. Pp. 8.

Gharaybeh, K. (2014). General Socio- Demographic Characteristics of the Jordanian Society: A study in Social Geography.4(1). Al Balqa applied University: Jordan.

Hall, S. (1996). The West and the Rest: Discourse and Power. Modernity: an Introduction to Modern Societies. Hall, Stuart, Held, David, Hubert, Don, and Thompson, Kenneth (ed). PP.184-227.

Henkemans, A., \& Francisca, S. (2013). "The use of hyperbole in the argumentation stage". OSSA Conference Archive. 159. http://scholar.uwindsor.ca/ossaarchive/ OSSA10/papersandcommentaries/159

Holmes, Janet. (2001). An Introduction to Sociolinguistics. $2^{\text {nd }}$ ed. Longman: Pearson Education Limited.

Jakobson, Roman. (1960). "Closing Statement: Linguistics and Poetics". Style in Language. Sebeok, Thomas A. (ed.). New York. London: The Technology Press of Massachusetts Institute of Technology and John Wiley \& Sons, Inc. pp: $350-377$.

Kaburise, P. (2005). Speech Act Theory And Communication: University of Pretoria etd.

McCarthy, M. (2004). “There's millions of them": hyperbole in everyday conversation. University of Nottingham. (36).

Omar, Z. K., and Khalaf, A.S. (2009). A Sociolinguistic Study of Hyperbole in Iraqi Arabic. Journal of Anbar University for language \& Literature, 1, 763-772.

Searle, J. (1976). A classification of illocutionary acts. Language in Society 5(1), 1-23.

Smith, J. (1969). Mystery of rhetoric unveiled, 1657. Menston: Scolar Press. Retrieved from: http://www. worldcat.org/title/mystery-of-rhetoric-unveiled- 1657/ oclc/638751127 Song, L. (2010). The Role of Context in Discourse Analysis. Qingdaoniversity, Qingdao: China. 1(6). pp. 876-879.

Yule, G. (1996). Pragmatics. New York: Oxford University Press.

Yule, G. (2006). The Study of Language. Cambridge University. Press 